\title{
The Performance of Socially Responsible Mutual Funds: The Role of Fees and Management Companies
}

\author{
Javier Gil-Bazo $^{1} \quad$ Pablo Ruiz-Verdú ${ }^{1} \quad$ André A.P. Santos $^{1}$
}

\begin{abstract}
In this paper, we shed light on the debate about the financial performance of socially responsible investment (SRI) mutual funds by separately analyzing the contributions of before-fee performance and fees to SRI funds' performance and by investigating the role played by fund management companies in the determination of those variables. We apply the matching estimator methodology to obtain our results and find that in the period 1997-2005, US SRI funds had better before- and after-fee performance than conventional funds with similar characteristics. The differences, however, are driven exclusively by SRI funds run by management companies specialized in SRI. While these funds significantly outperform similar conventional funds, funds run by companies not specialized in SRI underperform their matched conventional funds. We find no significant differences in fees between SRI and conventional funds except in one case: SRI funds are cheaper than conventional funds run by the same management company.
\end{abstract}

Keywords: Socially responsible investment; Mutual fund fees; Mutual fund performance. JEL classification codes: G12; G20; G23; A13.

The authors thank Sally Gunz (the Section Editor) and two anonymous reviewers for their comments, which have led to substantial improvements in the paper. We are also grateful to Manuel Bagüés, Iraj Fooladi, Vasiliki Skintzi, and seminar participants at Universidad Carlos III de Madrid, 2008 European Conference of the Financial Management Association, 2008 European Financial Management Association Meeting, and 2008 Spanish Finance Association Meeting for helpful comments and suggestions. The usual disclaimer applies. The financial support of Spain's Ministry of Education and Science (SEJ2005-06655, SEJ2007-67448 and CSD2006-00016) and the Madrid Autonomous Region (S2007/HUM0413) is gratefully acknowledged. 
Whether or not investing in SRI funds carries a price in terms of a reduced financial performance is an essential question for those investors who are concerned about the ethical consequences of their investments and, at the same time, want to obtain an adequate financial return from those investments. Previous research on socially responsible investment (SRI) mutual funds has, thus, focused on comparing the financial performance of SRI and conventional funds. In this paper, we make four main contributions to the debate on the financial performance of SRI funds. First, we make a clear distinction between the two components of mutual fund net financial performance: before-fee performance and fees. According to standard portfolio choice theory, constraining the investment opportunity set cannot improve performance. Since one of the defining characteristics of most SRI funds is that they exclude from their investment universe companies from sectors such as tobacco, alcohol, or gambling, it follows that their before-fee risk-adjusted performance should be no higher than the one they could obtain if they lifted those restrictions. While the implicit assumption in most previous work is that differences in performance between SRI and conventional funds, if any, would be due to differences in SRI funds' ability to generate risk-adjusted returns, differences in reported performance (which is net of fund expenses) could as well be due to differences in fees. ${ }^{1}$ By investigating before-fee performance we can evaluate directly whether SRI funds underperform conventional ones, without the potentially confounding effect of fees. Second, explicitly analyzing fees allows us to determine whether investors in SRI funds pay an explicit price for the ethical value of their investments. Our results also shed light on the way in which mutual fund fees are determined, particularly on the question of whether fees simply reflect funds' operating costs or, as argued by Christofersen and Musto (2002) and Gil-Bazo and Ruiz-Verdú (2009), they are set taking into account the performance sensitivity of funds' clienteles. This is especially relevant in the context of the recent debate in the literature regarding the sensitivity of SRI fund investors to performance (Bollen, 2007; Renneboog et al., 2008a; and Benson and Humphrey, 2008).

Third, we analyze the role of fund management companies in determining the differences between SRI and conventional funds. Despite the key influence of mutual fund management 
companies over fees and performance, their role has not been previously investigated in the literature on SRI. This is particularly relevant because estimated differences between SRI and conventional funds may not be due to the socially responsible investing per se, but to differences between the companies that manage SRI funds and those that manage conventional funds.

Finally, we improve upon the matched-pair analysis employed in several prior studies by using the matching estimator methodology of Abadie and Imbens (2006). This methodology provides a systematic procedure to find matches when matching is done on several variables simultaneously, as well as a method to adjust for the bias that arises when matches with identical values of the matching variables are not available.

To derive our empirical results, we obtain a sample of equity SRI funds from the Social Investment Forum for the period 1997-2005 and merge this sample with the CRSP Survivor Bias Free US Mutual Fund Database. Our results indicate that the SRI constraint does not reduce funds' before-fee performance, measured using the four-factor alpha of Carhart (1997). On the contrary, SRI funds outperform comparable conventional funds by a substantial $0.96 \%$ to $1.83 \%$ per year before expenses. We investigate whether differences in before-fee performance between SRI and conventional funds are due to differences in fund turnover, which has been documented to have a negative effect on fund performance (Carhart, 1997). We find that SRI funds exhibit lower turnover, but this cannot explain the performance differential between SRI and conventional funds.

We do not find economically or statistically significant differences in fees (expenses, loads, or a measure of the total ownership cost of mutual fund shares) between SRI and similar conventional funds. Therefore, either there are no significant differences in the way fees are set for SRI and conventional funds, or the effects of those differences cancel out on average.

Consistent with the results for before-fee performance and fees, we find that SRI funds obtain a higher after-fee risk-adjusted performance in terms of four-factor alpha than similar conventional funds.

To evaluate the robustness of our results, we repeat the tests separately for the 1997-2001 and 2002-2005 subperiods and find that SRI funds outperform conventional funds in both 
subperiods although not by a statistically significant amount. Differences in performance are substantially higher in the 1997-2001 subperiod, suggesting that the outperformance of SRI funds that we document in this paper is largely driven by the first part of the sample period. We also investigate how our results are affected by the presence of SRI funds that perform little social screening. When we restrict the sample of SRI funds to include only those funds that perform intensive social screening, we obtain results similar to those obtained for the whole sample of SRI funds. Similarly, excluding funds that outsource social screening activities does not alter our conclusions regarding the differences between SRI and conventional funds. To control for management company effects, we compare SRI and conventional funds run by the same management company and find that performance differences become small and statistically insignificant. These results suggest that differences between SRI and conventional funds may be explained by management company-level factors that determine both fund performance and the company's decision to manage SRI funds. We further explore this issue by distinguishing between SRI funds run by management companies specialized in SRI and those run by generalist companies. Our results show that SRI funds managed by generalist companies actually underperform, both before and after fees, similar conventional funds, although the difference is not highly statistically significant in all specifications. SRI funds run by specialized management companies, however, outperform comparable conventional funds by more than 2.6\% annually. This difference is substantial and highly statistically significant in all specifications. These results are consistent with two different hypotheses. First, unobservable factors at the management company level could be associated with both the decision to specialize in SRI funds and higher fees and performance. In this case, socially responsible investing itself would not have any effect on performance or fees. Alternatively, socially responsible investing could be associated with superior performance but only management companies that specialize in SRI would be able to exploit this advantage.

Most previous research has failed to find differences between the average performance of SRI and conventional funds in the US. ${ }^{2}$ Hamilton et al. (1993) find that young SRI funds outperform a random sample of conventional funds in the period 1981-1990 (with performance 
defined as after-expense Jensen's alpha), although results revert for seasoned funds. Benson et al. (2006) use an eight-factor model to account for differences in industry allocations and find that SRI funds underperform randomly chosen conventional funds in the period 1994-2003. Neither of these studies documents statistically significant differences in performance. Statman (2000) compares the performance of a sample of SRI funds with that of a control group of conventional funds of similar size and reports that the average Jensen's alpha of SRI funds is higher than that of the control group in the period 1990-1998, although the difference is only marginally significant. Bauer et al. (2005) and Renneboog et al. (2008a) use Carhart's (1997) four-factor model to measure fund performance. Although Bauer et al. (2005) do not find significant differences in four-factor alpha between US SRI funds and conventional funds matched on age and size in the 1990-2001 period, they show that the difference in performance between SRI and conventional funds improves (and becomes significant) in the subperiod from 1998 to 2001. Renneboog et al. (2008a) report no significant difference in four-factor alpha over their full 1991-2003 sample period. However, they find that SRI funds significantly underperform conventional funds in the 1991-1995 subperiod but outperform conventional funds in the 2000-2003 subperiod (although not by a statistically significant amount). The empirical evidence for other countries suggests that SRI funds do not outperform conventional funds (Gregory et al., 1997, Hamilton et al., 1993, Kreander et al., 2005, Bauer et al., 2007, Renneboog et al., 2008a).

Fees have not received much explicit attention in the literature on SRI mutual funds. However, several papers report average expense ratios for SRI and conventional funds (Statman, 2000; Bauer et al., 2005; Benson et al., 2006; Benson and Humphrey, 2008; Renneboog et al., 2008a). In line with our results, none of these papers find significant differences in fees between SRI and comparable conventional funds with the exception of Benson and Humphrey (2008), who report that the median expense ratio is significantly higher for conventional funds.

The paper is organized as follows. In Section 1 we describe the fee structure of US mutual funds and the data set. In Section 2 we discuss how we estimate risk-adjusted returns. We describe the matching estimator methodology and our empirical results in Section 3. In Section 
4 we analyze the role of management companies. Finally, we conclude in Section 5.

\section{Data}

\subsection{The fee structure of US mutual funds}

Mutual funds charge two kinds of fees: expenses and loads. Expenses comprise the management fee (typically a fixed percentage of assets under management) and other recurring operating costs—such as custodian, administration, accounting, registration, and transfer agent fees. Rather than charging explicit fees for these expenses, funds deduct them on a daily basis from the fund's net assets. Expenses are expressed as a percentage of assets under management (the expense ratio). Loads are one-time fees used to compensate distributors. They are paid either at the time of purchasing (front-end load) or redeeming fund shares (back-end load) and computed as a fraction of the amount invested.

Since the 1980s many funds charge 12b-1 fees, which are used to pay for marketing and distribution costs and are included in the fund's expense ratio. Many funds offer multiple share classes (such as A, B, or C classes) with different combinations of loads and $12 \mathrm{~b}-1$ fees. To approximate the total cost of mutual fund shares, we aggregate all the costs incurred by fund shareholders using the now standard total ownership cost (TOC) measure introduced by Sirri and Tufano (1998). To obtain this measure, we annuitize the total load by dividing it by the number of years that investors are expected to hold the mutual fund shares. Following Sirri and Tufano (1998), we assume a seven-year holding period, and, thus, define total ownership cost as TOC $=$ expense ratio $+($ total load/7).

\subsection{Sample selection}

Our main source of data is the CRSP Survivor-Bias Free US Mutual Fund Database (see Carhart, 1997; Carhart et al., 2002; and Elton et al., 2001, for detailed discussions of the data set). We obtain monthly information on returns, and yearly information on fees and other fund 
characteristics for all domestic, diversified, equity mutual funds in the database for the period December 1994-December 2005. We consider a fund to be a domestic, diversified, equity mutual fund if it belongs to any of the following Standard \& Poor's Detailed Objective Codes as reported by CRSP: Aggressive Growth, Growth Mid Cap, Growth and Income, Growth, Small Company Growth.

In the CRSP data set, different classes of the same fund appear as different funds. We identify the classes that belong to the same fund and obtain fund-level information by averaging (weighting the classes by total net assets) the class-level data provided by CRSP. We also exclude index funds from our sample. Since the index identifier in CRSP is only available as of 2003, we use funds' names to determine whether they are index funds or not. For SRI funds, we double-check the classification manually to make sure that we do not unnecessarily delete SRI funds from the sample. We follow a similar procedure to identify institutional classes. Since funds often have both retail and institutional classes, we classify a fund as institutional if more than fifty percent of its assets are in institutional classes. Institutional funds are excluded from the sample.

We obtain our list of SRI funds from the Social Investment Forum's (SIF) reports published in 1997, 1999, 2001, 2003, and 2005. ${ }^{3}$ Each report contains comprehensive information about SRI in the US for both the publication year and the preceding one. In particular, the reports contain a list of SRI mutual funds compiled by SIF. To construct this list SIF employs a direct survey methodology and gathers information from third parties. A fund is included in the SIF list if it utilizes one or more social or environmental criteria as part of a formal investment policy. ${ }^{4}$ To be included in the list funds are required to provide written confirmation of social screening when not explicitly incorporated into the fund prospectus. Furthermore, SIF performs checks to exclude any institution that says it takes into account social or corporate governance criteria in its investment decisions but lacks a formal policy for doing so or has a policy but does not observe it.

To build our sample of SRI funds, we first labeled a mutual fund as SRI in a given year if it was included in the corresponding SIF report. Some SRI funds included in some reports, 
however, do not appear in others, despite being alive. We checked funds' prospectuses to identify whether these changes were due to changes in the SRI orientation of the funds and found that temporary exclusions from the reports were not associated with any significant change in reported investment strategy ${ }^{5}$ Thus, we label a fund as SRI for the whole sample period if the fund appears at least once in the SIF reports.

We obtain information from SIF on the social screening activity of SRI funds. SIF pro vides information about the use of screens in eleven screening categories: alcohol, tobacco, gambling, defense/ weapons, animal testing, products/services, environment, buman rights, labor relations, employment/equality, and community investment. We also obtain information from SIF on whether social screening is performed in-house or delegated to an external firm.

In our tests, we exclude from the sample those observations of SRI and conventional funds with missing values for risk-adjusted performance (Section 2 describes the procedure employed to estimate risk-adjusted performance), expenses, loads, or any of the control variables (investment objective, total net assets, age, and total net assets of the management company). An important feature of our sample is that it is free of survivorship bias, since the CRSP data set contains information on all funds operating during the entire sample period and since we obtained historical lists of SRI funds from SIF.

Our final sample of actively managed, retail, domestic, US, equity mutual funds in the 1997-2005 period contains a total of 455 SRI and 8,476 conventional fund-year observations, that correspond to 86 SRI funds and 1,761 conventional funds, respectively. Table 1 displays both the number and total assets under management for each group of funds by year. Table 2 reveals several differences between SRI and conventional funds. First, average and median total loads are lower for SRI funds. Since almost $40 \%$ of all SRI funds and one third of all conventional funds in the sample never charge loads, we also compute the average and median total loads only for funds that charge positive loads and find that mean and median total loads are also lower for SRI load funds than for conventional load funds. Second, the companies that manage SRI funds are smaller than those managing conventional funds. Third, average size (measured as total net assets in millions of dollars) is larger, but median size smaller, for SRI 
funds. Fourth, the turnover ratio (defined as the minimum of aggregate sales and aggregate purchases of securities, divided by the average 12-month total net assets of the fund) is substantially higher for conventional funds. Finally, both the before- and after-fee raw returns of conventional funds are slightly higher than those of SRI funds.

\section{Estimation of risk-adjusted returns}

Following a long list of studies in the mutual fund performance evaluation literature, ${ }^{6}$ we employ Carhart's (1997) four-factor model to estimate risk-adjusted performance:

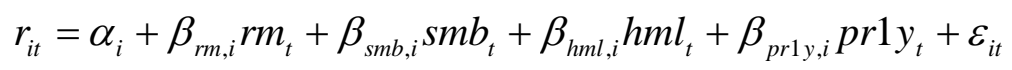

where $r_{i t}$ is fund $i$ s before-expense return in month $t$ in excess of the 30-day risk-free interest rate-proxied by Ibbotson's one-month Treasury bill rate; $r m t$ is the market portfolio return in excess of the risk-free rate; and $s m b t$ and $h m l_{t}$ denote the return on portfolios that proxy for common risk factors associated with size and book-to-market, respectively. The term $p r 1 y t$ is the return difference between stocks with high and low returns in the previous year, and is included to account for passive momentum strategies by mutual funds. ${ }^{7}$ The term $\alpha_{i}$ is the four-factor alpha and captures the fund's risk-adjusted performance according to Carhart's model. For comparison with previous studies, we also consider Jensen's alpha, estimated using the market return $r m t$ as the single risk factor.

We follow Carhart's (1997) two-stage estimation procedure to obtain a panel of monthly fund risk-adjusted performance estimates. In the first stage, for every month, $t$, in years 19972005, we regress fund excess returns on the risk factors over the previous three years. If less than three years of previous data are available for a specific fund-month, we require a minimum of 30 monthly observations in the previous three years. In the second stage, we estimate a fund's risk-adjusted performance in month $t$ as the difference between the fund's before-expense excess return and the realized risk premium, defined as the vector of betas times the vector of factor 
realizations in month $t$. Finally, we obtain each fund's risk-adjusted performance as the average of the annualized monthly alphas over the fund's life in the sample.

\section{Differences between SRI funds and conventional funds}

\subsection{Empirical strategy}

The ideal experiment to evaluate the impact of socially responsible investing on performance and fees would be to observe the same funds both with and without the SRI constraint. Most previous studies (Gregory et al., 1997; Statman, 2000; Kreander et al., 2005; Bauer et al., 2005) approximate the ideal experiment by comparing the performance of SRI funds to that of a control group of comparable conventional funds, a methodology that is known as matched-pair analysis. More precisely, each SRI fund is matched to one or several conventional funds with similar values of one or more matching variables. The difference between SRI and conventional funds is then estimated by averaging the differences between each SRI fund and the corresponding matched conventional funds. Finding control observations, however, is not easy when matching is done on several control variables, since exact or nearly exact matches for all variables and observations are rare even in large data sets (Zhao, 2004). In this paper, we employ the bias-adjusted matching estimator developed by Abadie and Imbens (2006), which overcomes this difficulty. The matching estimator analysis maps the multiple matching variables into a single number that measures the distance to the observation to be matched and selects as control observations those with the lowest value for this distance. Matching estimators, therefore, make it possible to use several matching variables simultaneously. ${ }^{8}$ The bias-adjusted matching estimator of Abadie and Imbens further corrects the potential bias arising from the difference in the matching variables by explicitly taking into account how the variable of interest (fees or performance) is related to the matching variables. ${ }^{9}$

To estimate the differences between SRI and conventional funds, we first compute for each fund the average value over the sample period of each of the different measures of performance and fees and fund turnover (the outcome variables). We then match each SRI fund with 
conventional funds that, in the year in which the SRI fund first appears in the sample, have the same investment objective as the SRI fund and have similar age, size, and size of the fund's management company. Therefore, we match SRI funds with conventional funds that are initially similar and estimate the differences over time in performance and fees between the initially similar funds. We report results for simple and biased-adjusted estimators obtained using one and four matches per SRI fund. The one-match procedure is the one that most closely approximates the matched-pair methodology used in previous studies and it maximizes the quality of the matches, although at the cost of a small sample size. In some specifications, we use two, rather than four matches, because of a low number of available fund-year observations.

\subsection{Differences in before-fee performance}

In Panel A of Table 3, we report the average before-fee performance of all SRI and all conventional funds in the sample. The results indicate that SRI funds on average outperform conventional funds before fees by $89 \mathrm{bp}, 1.03 \%$, and $1.43 \%$ in terms of unadjusted returns, onefactor alpha, and four-factor alpha, respectively. However, the difference in these unconditional means is statistically significant only when performance is measured using the four-factor alpha.

Panel A in Table 4 reports our estimates of the difference in before-fee performance between SRI and conventional funds using the matching estimators methodology. The difference in raw (risk-unadjusted) before-fee returns between SRI funds and similar conventional funds is negligible in all specifications and not statistically significant in any of them. SRI funds also earn higher one-factor alphas, although the difference is statistically significant only in some of the specifications. However, differences in four-factor alpha are statistically significant in all specifications. They are also larger than those estimated for raw returns and economically significant: SRI funds earn an annual four-factor alpha that is between $0.96 \%$ and $1.83 \%$ higher than the one earned by matched conventional funds. This difference is substantial, considering that the mean four-factor alpha for SRI funds is $0.58 \%$.

We can extract two conclusions from Panel A of Table 4. First, the facts that differences in 
raw performance are negligible, but differences in risk-adjusted four-factor alpha are substantial and statistically significant show that SRI and conventional funds differ in their exposure to the different risk factors. In unreported results we find that the main difference between SRI and conventional funds is that SRI funds exhibit a smaller exposure to the momentum factor. Second, the risk-adjusted before-fee returns of SRI funds are higher than those of comparable conventional funds. We consider several possible explanations for this result.

First, the large size of the investment universe faced by fund managers implies that they must make choices about the breadth and depth of their analysis. Restricting the investment universe may prove optimal if depth is relatively more profitable than breadth (see Nieuwerburgh and Veldkamp, 2005). Recent evidence showing that fund families following more focused investment strategies (Nanda et al., 2004) and mutual funds holding portfolios concentrated in specific industries tend to perform better (Kacperczyk et al., 2005) provides support for this hypothesis. Mutual funds' preference for investing in firms with headquarters located near those of the management company (Coval and Moskowitz, 1999, 2001) also provides support for the idea that fund managers often choose to restrict their investment universe. The performance premium of SRI funds could, thus, stem from the gains from specialization induced by their investment restrictions. SRI constraints could also have a positive impact on performance if limiting the set of investment opportunities reduces excessive trading. The transaction costs generated by excessive trading are directly deducted from funds' assets (transaction costs are not part of fund expenses) and, thus, directly affect before-fee returns. To explore this possibility, we estimate the difference between the turnover ratio of SRI and conventional funds and find (Panel B in Table 4) that SRI funds have a lower portfolio turnover than comparable conventional funds. However, the difference in turnover cannot explain the performance difference between SRI and conventional funds, as shown in Table 4 (Panel A), which reports the estimated differences in before-fee (but net of transaction costs) performance between SRI and conventional funds when turnover is used as an additional matching variable.

The performance advantage of SRI funds could also be explained by differences in the 
severity of the conflict of interest between investors (who seek high risk-adjusted returns) and fund managers (who want to maximize fee revenues net of management costs). If SRI is associated with better fund governance, and if agency problems have a significant effect on performance, then SRI funds could exhibit better performance than conventional funds.

Finally, the requirements that a fund has to fulfill in order to be included in the SIF's listing of SRI funds are not stringent. For example, a fund could be on the list just by having a formal policy of excluding companies with interests in the tobacco business. If the constraints that SRI (as defined in our data set) imposes on fund managers are minor, the performance of SRI mutual funds should not be expected to be lower than that of conventional funds. It is important to highlight that the estimated performance differences between SRI and conventional funds cannot be explained by (nor require) a performance premium for socially responsible firms. If these firms yielded higher risk-adjusted returns, conventional funds could obtain returns as high as those of SRI funds by investing in SRI firms, since conventional funds are not restricted to investing in firms that are not socially responsible. ${ }^{10}$

\subsection{Differences in fees}

Even if socially responsible investment does not impose a cost on SRI fund investors in terms of reduced before-fee financial performance, these investors could still pay an explicit price for their funds' social responsibility in the form of higher fees. Indeed, there are reasons to expect fees charged by SRI funds to be higher. First, some SRI funds actively engage with the firms in which they invest to encourage them to pursue socially responsible policies. The costs of such active monitoring may be partly passed on to investors in the form of higher expenses. Second, investors concerned about social responsibility may be willing to pay a premium for the SRI attribute. Finally, investors in SRI funds may differ from other investors in their sensitivity to financial performance. It is well known that investor sensitivity to performance differs across funds (Sirri and Tufano, 1998). Further, Christofersen and Musto (2002) and Gil-Bazo and Ruiz-Verdú (2009) show that fund fees are higher in funds facing less performance-sensitive 
investors. Therefore, if SRI fund investors were less sensitive to after-fee performance, one would expect SRI funds to charge higher fees. The empirical evidence on the performance sensitivity of SRI mutual fund investors, however, is mixed. Bollen (2007) finds that flows of money to SRI funds in the US are more sensitive to performance than flows to conventional funds when returns in the previous year are positive, and less sensitive when past returns are negative. Renneboog et al. (2006) report similar evidence for a sample of international funds, although they also find that flows of money to SRI funds are not negatively affected by fund management fees or loads, contrary to conventional funds. However, more recent evidence for the US market (Benson and Humphrey, 2008) suggests that, overall, SRI fund flow is less sensitive to returns than conventional fund flow. These authors, however, also find little differences in sensitivity to fund expenses, which is low both for conventional and SRI funds.

Panel C in Table 3 reports the average expenses for all SRI funds and all conventional funds in the sample. The average expense ratio of the sample of SRI funds is slightly lower than the average expense ratio in the sample of all conventional funds and the difference is not statistically significant. Table 5 contains the results of the matching estimator analysis for differences in fees. In line with the comparison of the unconditional means, the table shows that the difference in the expense ratio of SRI and similar conventional funds is negligible. Thus, while the average expense ratio of SRI funds is 134.45 basis points, estimated differences range between -1.31 and -3.57 basis points. Further, none of the differences are statistically significant at conventional significance levels.

From these results, however, one cannot conclude that investors in SRI funds pay the same fees as those investing in conventional funds, since, on top of expenses, mutual funds often charge loads. To address this issue and shed light on the pricing policies of SRI and conventional funds, we estimate the difference in the loads charged by SRI and conventional funds. As we report in Table 5, there is no conclusive evidence that SRI and conventional funds charge different loads. While SRI funds are estimated to charge higher loads when we perform a single match per SRI fund, the estimated difference turns negative when we use four matches. Further, the difference is not statistically significant in both cases. To complete the analysis, we 
also estimate the difference in total ownership costs, which include both expenses and loads. As expected from the previous results, differences in total ownership costs are small and not statistically significant. Our conclusions do not change if, instead of a seven-year holding period, we assume that investors hold their shares for either five or ten years. ${ }^{11}$

We can conclude from Table 5 that SRI funds do not charge significantly higher fees than their conventional counterparts. Why this is the case is an open question. One possibility is that the price sensitivity of US investors in SRI funds does not differ from that of investors in conventional funds, as suggested by Benson and Humphrey (2008) (who, however, find that SRI investors are less sensitive to performance). Our results are also compatible with investors in SRI funds being willing to pay a premium for SRI funds (which would increase average fees for these funds) and at the same time being more sensitive to fees (which would reduce average fees for these funds), because the smaller number of SRI funds as compared to conventional funds makes price comparisons easier for SRI funds or because investors in SRI funds are more financially sophisticated. However, our results could also be compatible with a lower price sensitivity by SRI investors (which would lead, other things equal, to higher fees) together with a greater regard for investors' interests by SRI fund management companies (which would lead, other things equal, to lower fees). Finally, given the relatively small size of the SRI sample, the lack of a statistically significant difference in fees between SRI and matched conventional funds could also be due to sampling error.

\subsection{Differences in after-fee performance}

The results above show, on the one hand, that SRI funds outperform comparable conventional funds before fees and, on the other hand, that SRI funds do not charge higher fees. Panel B in Table 3 shows that average after-fee performance is higher in the sample of SRI funds than in the sample of all conventional funds: SRI funds outperform conventional funds on average by $1.04 \%$ if performance is measured as one-factor alpha and by $1.44 \%$ in terms of four-factor alpha. Further, the difference is statistically significant at the $10 \%$ level for the one-factor alpha 
and at the $1 \%$ level for the four-factor alpha. Panel $\mathrm{C}$ in Table 4 shows the results of the matching estimator analysis for differences in after-fee performance. Again, we find results in line with those obtained from the comparison of the unconditional means. The after-fee performance of SRI funds is higher than that of matched conventional funds for both performance measures. Although the difference in one-factor net alpha is not significant in all cases, estimated differences in four-factor after-fee alphas are significant and substantial in all specifications (between $0.99 \%$ and $1.85 \%$ ). Therefore, SRI funds outperform similar conventional funds both before and after fees in terms of four-factor alphas.

Our results for one-factor alphas are consistent with previous studies of the US market that report differences in this measure of performance (e.g., Statman, 2000; Bauer et al., 2005; Renneboog et al., 2008a). Like those studies, we cannot conclude unambiguously that the performance of SRI funds differs from that of conventional funds when measured as one factor alpha, although we do find a performance advantage for SRI funds that is statistically significant in some of our comparisons.

Our results for four-factor alphas can be compared to those reported by Bauer et al. (2005) and Renneboog et al. (2008a) since these authors also use Carhart's (1997) four-factor model to estimate risk-adjusted performance and some of the subperiods that they study overlap with our sample period. As mentioned in the introduction, Bauer et al. (2005) find that SRI funds significantly outperform conventional funds matched on age and size in the 1998-2001 subperiod, while Renneboog et al. (2008a) find that SRI funds outperformed conventional funds in the 2000-2003 subperiod, although not by a statistically significant amount. Therefore, our results are closer to those of Bauer et al. (2005) in that we also find evidence that SRI funds have significantly outperformed conventional funds in terms of four-factor alphas.

\subsection{Robustness Checks}

\subsubsection{Analysis by subperiods}


Previous studies have reported different results when comparing SRI and conventional funds in different subperiods (e.g., Bauer et al., 2005; Renneboog et al., 2008a). These findings suggest that different sample periods may lead to different conclusions about the performance of SRI funds relative to that of conventional funds. To evaluate the extent to which our results are driven by part of the sample period, we split the sample period in two subperiods. The first subperiod covers the first five years of our sample (1997 to 2001) and the second subperiod covers the last four years (2002 to 2005). We report the results of the matching estimator analysis by subperiods in Table 6 .

In the subperiod from 1997 to 2001 SRI funds outperform comparable conventional funds by more than $1 \%$ both before and after expenses. SRI funds also charge fees that exceed those of conventional funds with similar characteristics, but the difference is small (between 3.5 and 8.5 bp). Neither differences in performance nor differences in fees are statistically significant. The lack of statistical significance, however, could be caused by the fact that by splitting the sample we reduce sample size and, therefore, the power of the tests.

In the last four years of the sample, we also find that SRI funds outperform matched conventional funds both before and after fees. However, the difference is smaller than in the first subperiod in all specifications. SRI funds also have a higher ownership cost than matched conventional funds but the difference is negligible. As in the first subperiod none of the differences are statistically significant. We may, therefore, conclude that the outperformance of SRI funds documented for our entire sample period is mainly driven by the first part of the sample period.

To explore further how performance differences between SRI and conventional funds have evolved over time, we also perform a year-by-year analysis. For every year in our sample period, we obtain the matching estimator (one match, bias corrected) of the difference in beforefee four-factor alphas. In unreported results, we find that the before-fee risk-adjusted performance of SRI funds exceeds that of conventional funds every year in the sample period, although the difference is statistically significant in only three years. ${ }^{12}$ 


\subsubsection{Matching Procedure}

A possible concern about our results is that they may be sensitive to the moment in which we match each SRI fund with the corresponding conventional funds. As discussed by Kreander et al. (2005), the quality of the matches worsens for periods that are far away from the time of matching. In small samples, this lower quality of the matches may lead to imprecise estimates and, potentially, the choice of matching period may also introduce biases. For example, if SRI funds do not have the same life span as the conventional funds with which they are matched, survivorship biases may emerge (see, e.g., Gregory and Whittaker, 2007). Further, differences in life spans may also introduce biases because estimated average performance is time-varying. Indeed, Lynch and Wachter (2007) show that mutual fund performance moves with the business cycle. Apparent differences in performance could thus arise because the performance of SRI and conventional funds is measured over different periods.

To check whether our results are robust to these potential problems, we also match each SRI fund-year observation with conventional fund-year observations of the same year, with the same investment objective, and with similar fund size, age, and size of the fund's management company (all in logs). That is, we compare fund-year observations of SRI funds with contemporaneous fund-year observations of conventional funds with similar characteristics. In results not reported, but available from the authors upon request, we find that the risk-adjusted performance of SRI funds, measured as annual four-factor alpha, is higher than that of similar conventional funds both before and after fees. Further, the estimated differences are similar to those reported in Table 4 and highly statistically significant. We also obtain essentially the same results for turnover and when we use turnover as a matching variable in the estimation of performance differences. As in Table 5, we estimate very small fee differences between SRI and conventional funds. However, these differences are consistently positive and statistically significant, suggesting that SRI funds might charge higher fees than similar conventional funds. This last result, however, should be interpreted with care, since statistical significance is likely to be greatly overstated when we match fund-year observations. The reason for this overstatement is that when matching fund-year observations, we use several observations of the 
same fund. Since fees are very persistent over time, observations of the same fund will be strongly correlated. This strong correlation, in turn, implies that the standard errors of the coefficients are likely to be underestimated and, as a result, that the statistical significance of the estimated coefficients is likely to be overstated (see Petersen, 2009, for a discussion of this issue in the context of regression analysis). In any case, the economic significance of the differences is small and it does not alter the result that SRI funds have a higher after-fee performance than similar conventional funds.

\subsubsection{Social Screening Intensity}

As mentioned in Subsection 3.2, funds with little social screening are not likely to differ too much from conventional funds, so their inclusion in the SRI sample could conceal otherwise large differences between SRI and conventional funds. A similar concern could be raised about funds in which social screening is outsourced rather than performed in-house by the fund's management company. To investigate this possibility, we use the information provided by SIF on the screens employed by SRI funds and on whether screening is carried out in-house or outsourced, and perform separate analyses for different groups of SRI funds. Unfortunately, information on screen categories and on the venue of social screening is available for only 28 and 30 funds in our SRI sample, respectively. Therefore, our analysis is limited by the size and representativeness of these subsamples.

Results in Table 7 show that SRI funds with intensive screening (defined as those that use a number of screens greater than or equal to the sample median of 10 screens) outperform their conventional counterparts, although this difference is not significant in all specifications. ${ }^{13}$ Furthermore, these funds outperform their control group of conventional funds by a higher amount than funds with fewer screens. Unlike moderately screened funds, intensively screened funds are more expensive than their conventional control group, although this difference is not statistically significant.

Results in Table 8 suggest that both SRI funds that do all social screening in-house and funds that use some external screening outperform their conventional peers, although these 
differences are not significant in some specifications for funds using in-house screening. ${ }^{14}$ Estimated differences in total ownership costs between SRI and conventional funds are neither significant nor clearly larger for either group of SRI funds.

Therefore, excluding from the SRI sample funds that use few screens or funds that outsource the screening activity does not yield qualitatively different results from those reported in Tables 4 and $5 . .^{15}$

\section{The role of management companies}

Previous sections, as well as extant work on the performance of SRI mutual funds, compare SRI mutual funds with conventional funds that have similar characteristics. Mutual fund performance and fees, however, are not determined exclusively at the level of the individual fund. Mutual funds are operated by management companies, and the resources, policies, and culture of these companies play an important role in the determination of individual funds' performance and fees. Management companies differ in their ability to attract and retain talented managers, the incentives provided to these managers, the availability of supporting staff, their technology, their ability to negotiate prices with other service providers (such as brokers), their advertising policies, and the governance of their funds. ${ }^{16}$ In previous sections, we partly controlled for the influence of the management company by including management company size as one of the matching variables. Using observable company characteristics as matching variables, however, may be insufficient to control for those management company traits most relevant for the determination of performance or fees.

To filter out the impact of unobserved management company heterogeneity, we match SRI funds with conventional funds with similar size and age, and managed by the same management company. As reported in Table 9, differences in performance, both before and after fees, between SRI and similar conventional funds run by the same company are not statistically significant. They are also smaller than the corresponding estimated differences reported in Table 
4. The differences in performance between SRI and conventional funds reported in previous sections, therefore, might be largely explained by differences in unobserved characteristics of management companies that are more likely to offer one type of fund or the other. However, our results also show that SRI funds have a lower total ownership cost than conventional funds managed by the same management company and the difference (of at least 22 basis points) is both statistically and economically significant. ${ }^{17}$ Therefore, management companies that offer both conventional and SRI funds do not seem to charge a fee premium for the latter. On the contrary, SRI funds are cheaper than similar conventional funds.

These results, however, should be interpreted with care. First, the subsample of funds employed to obtain these results is substantially smaller than the full sample. In particular, while there are 86 SRI funds and 1,761 conventional funds in the original sample, the subsample of management companies offering both types of funds contains 27 SRI and 108 conventional funds, respectively. Thus, restricting the set of conventional funds that can serve as controls to those in the same management company as the corresponding SRI fund necessarily leads to poorer matches. Further, the restricted subsample of SRI and conventional funds may not be representative of the whole population. Indeed, funds run by management companies offering both types of funds are both larger and older than funds in the unrestricted sample.

As a second approach to determine the role of fund management companies, we hypothesize that management company specialization in the management of SRI funds is key in explaining the differences between SRI and conventional funds. Under this assumption, we can use companies' degree of specialization to control for relevant management company characteristics without requiring control observations to belong to the same management company. To do this, we divide the sample of SRI funds into two subsamples: one containing funds managed by companies that specialize in SRI funds (defined as those that have more than 50\% of their assets in SRI funds) and the other one containing funds managed by generalist companies (which manage SRI funds, but have less than $50 \%$ of their assets in this type of fund). We would like to compare SRI funds with similar conventional funds run by the same type of management company (specialized or generalist). Unfortunately, there are only five conventional funds run 
by companies specialized in SRI funds, which are not enough to match 66 SRI funds run by this type of management company. Therefore, we perform this kind of comparison only for generalist companies. Panel A of Table 10 shows that SRI funds run by generalist companies underperform, both before and after fees, conventional funds also run by generalist companies by an amount between $3.09 \%$ and $4.24 \%$, although these differences are not statistically significant when we do not use the bias correction procedure. SRI funds are associated with a higher total ownership cost, but, again, this difference (between 3.47 and 5.62 basis points) is small and not statistically significant. These results are, therefore, in line with those of Table 9, and suggest that management company characteristics may explain the performance differences between SRI and conventional funds that we find when we analyze the whole sample SRI funds.

Our results, however, are still subject to the criticism that funds in generalist companies may not be representative of the rest of the population. For instance, conventional funds in generalist companies could have higher performance and fees than conventional funds managed by other kinds of companies. In order to discard this possibility, we also compare SRI funds in generalist companies with matched conventional funds run by all management companies. As Panel B of Table 10 shows, differences in before- and after-expense performance between SRI funds in generalist companies and matched conventional funds from the whole sample are slightly smaller than those reported in Panel A, but they are estimated more precisely (all performance differences are statistically significant at the $5 \%$ or $10 \%$ level) thanks to the larger sample of potential matches. The coefficients for the difference in total ownership cost once again change sign and are not statistically significant.

These results suggest that the differences between SRI and conventional funds reported in Section 3 are fully driven by SRI funds run by management companies specialized in SRI. Indeed, when we compare SRI funds run by specialized management companies with matched conventional funds run by all management companies (Panel C of Table 10), we find that SRI funds outperform conventional funds by as much as $2.76 \%$ before expenses and $2.70 \%$ after expenses and all differences are highly statistically significant. The total ownership cost of SRI funds exceeds that of matched conventional funds by less than 10 basis points and the difference 
is not statistically significant. Results (available from the authors upon request) are almost identical if specialized management companies are defined as those in which SRI funds represent $75 \%$ of total assets under management or more, and generalist companies as those with less than $75 \%$ of assets in SRI funds.

There are two possible explanations for the results of Table 10. First, companies that are more likely to deliver higher risk-adjusted returns and charge higher fees could also be more likely to specialize in SRI funds. For instance, more ethical management companies could be less prone to act against investors' interests, which would result in better performance. At the same time, they could be more inclined to manage SRI funds. SRI funds operated by these companies could, thus, outperform conventional funds, even if socially responsible investing per se did not increase performance. According to the second explanation, socially responsible investing itself would deliver superior performance, but this superiority would only be realized by management companies specialized in SRI. If the superior performance and higher fees of SRI funds in specialized management companies were due to the specific characteristics of these management companies and not to the SRI nature of these funds, then we would observe no differences between SRI funds and conventional funds in specialized companies. As mentioned above, however, we cannot perform this comparison due to the low number of conventional funds run by management companies specialized in SRI.

We note that the percentage of SRI funds that is run by specialized management companies goes down from $87 \%$ in 1997 to $76 \%$ in 2005 . If this trend continues, we may expect the average performance of all SRI funds to become closer to that of similar conventional funds.

It is important to note that our results do not imply that the optimal strategy for mutual fund investors is to invest in SRI funds managed by specialized companies. First, while the average performance of SRI funds is higher than that of conventional funds, the best conventional funds could still outperform the best SRI funds. If investors were able to detect the best performers, it would then be optimal, from the point of view of financial performance, to invest only in conventional funds. Further, while SRI funds perform better on average than similar conventional funds, the best conventional funds may be very different in size or age from 
conventional funds and, thus, may not be included in our control group. We cannot rule out that investing in these funds may yield a higher performance than investing in SRI funds. Indeed, Geczy et al. (2005) show that an optimal investment strategy in conventional funds may outperform a similarly optimal investment in SRI funds, while Renneboog et al. (2008a) report that the performance of a "smart-money" portfolio of SRI funds (constructed by tracking the inflows of new money into mutual funds) does not differ from that of a "smart-money" portfolio of conventional funds.

\section{Concluding Remarks}

In this paper we revisit the question of whether mutual funds constrained by a socially responsible investment strategy underperform mutual funds not subject to that constraint. To address this question, we separately investigate the contributions of before-fee performance and fees to the financial performance of SRI funds, and explicitly analyze the role played by mutual fund management companies in explaining observed differences between SRI and conventional funds. To obtain our results, we apply the matching estimator methodology to a panel of US equity funds in the period 1997-2005.

We provide evidence that investors do not pay a price, in the form of reduced performance, for investing in SRI mutual funds. On the contrary, investors in SRI funds have earned a premium in terms of superior risk-adjusted performance relative to that of similar conventional funds both before and after fees. At the same time, there is no conclusive evidence that SRI funds charge higher fees. We find, however, that the performance premium of SRI funds with respect to conventional funds is entirely due to SRI funds operated by management companies that specialize in the management of SRI funds. While SRI funds operated by companies specialized in SRI significantly outperform their conventional peers, SRI funds run by generalist companies underperform similar conventional funds. We also find that the difference in performance between SRI and conventional funds documented for the full 1997-2005 period is 
mainly due to the superiority of SRI funds in the first part of the sample period.

These results are of practical significance for investors. First, they show that SRI funds may outperform similar conventional funds. And second, they suggest that investors should take into account management company characteristics, particularly their specialization in SRI, when investing in SRI funds.

\section{References}

Abadie, A., D. Drukker, J. Herr and G. Imbens: 2004, 'Implementing Matching Estimators for Average Treatment Efects in Stata', The Stata Journal 4(3), 290-311.

Abadie, A. and G. Imbens: 2006, 'Large Sample Properties of Matching Estimators for Average Treatment Efects', Econometrica 74(1), 235-267.

Bauer, R., J. Derwall and R. Otten: 2007, 'The Ethical Mutual Fund Performance Debate: New Evidence from Canada', Journal of Business Ethics 70(2), 111-124.

Bauer, R., K. Koedijk and R. Otten: 2005, 'International Evidence on Ethical Mutual Fund Performance and Investment Style', Journal of Banking and Finance 29(7), 1751-1767.

Benson, K., T. Brailsford and J. Humphrey: 2006, 'Do Socially Responsible Fund Managers Really Invest Diferently?', Journal of Business Ethics 65(4), 337-357.

Benson, K. and J. Humphrey: 2008, 'Socially responsible investment funds: Investor reaction to current and past returns', Journal of Banking and Finance 32(9), 1850-1859.

Bollen, N.: 2007, 'Mutual Fund Attributes and Investor Behavior', Joumal of Financial and Quantitative Analysis 42(3), 683-708.

Carhart, M.: 1997, 'On Persistence in Mutual Fund Performance', The Journal of Finance 52(1), 5782.

Christofersen, S. and D. Musto: 2002, 'Demand Curves and the Pricing of Money Management', Review of Financial Studies 15(5), 1499-1524. 
Coval, J. D. and T. J. Moskowitz: 1999, 'Home Bias at Home: Local Equity Preference in Domestic Portfolios', The Journal of Finance 54(6), 2045-2074.

Coval, J. D. and T. J. Moskowitz: 2001, 'The Geography of Investment: Informed Trading and Asset Prices', Journal of Political Economy 109(4), 811-841.

Geczy, C., R. Stambaugh and D. Levin: 2005, 'Investing in Socially Responsible Mutual Funds', Working Paper, University of Pennsylvania.

Gil-Bazo, J. and P. Ruiz-Verdú: 2009, 'The relation between price and performance in the mutual fund industry', Journal of Finance, forthcoming.

Gregory, A., J. Matatko and R. Luther: 1997, 'Ethical Unit Trust Financial Performance: Small Company Efects and Fund Size Efects', Journal of Business Finance \& Accounting 24(5), 705-725.

Gregory, A. and J. Whittaker: 2007, 'Performance and Performance Persistence of Ethical Unit Trusts in the UK', Journal of Business Finance \& Accounting 34(7-8), 1327-1344.

Hamilton, S., H. Jo and M. Statman: 1993, 'Doing Well while Doing Good? The Investment Performance of Socially Responsible Mutual Funds', Financial Analysts Journal 49(6), 62-66.

Imbens, G.: 2004, 'Nonparametric Estimation of Average Treatment Efects under Exogeneity: A Review', Review of Economics and Statistics 86(1), 4-29.

Kacperczyk, M., C. Sialm and L. Zheng: 2005, 'On the Industry Concentration of Actively Managed Equity Mutual Funds', The Journal of Finance 60(4), 1983-2011.

Kreander, N., R. Gray, D. Power and C. Sinclair: 2005, 'Evaluating the Performance of Ethical and Non-ethical Funds: A Matched Pair Analysis', Journal of Business Finance \& Accounting 32(7-8), 1465-1493.

Lynch, A. and J. Wachter: 2007, 'Does mutual fund performance vary over the business cycle?', New York University and University of Pennsylvania, Working Paper.

Nanda, V., Z. Wang and L. Zheng: 2004, 'Family Values and the Star Phenomenon', Review of Financial Studies 17(3), 667-698. 
Nieuwerburgh, S. V. and L. Veldkamp: 2005, 'Information Acquisition and Portfolio Underdiversification', Working paper, New York University.

Petersen, M. A.: 2009, 'Estimating standard errors in finance panel data sets: Comparing approaches', Review of Financial Studies 22(1), 435-480.

Renneboog, L., J. T. Horst and C. Zhang: 2006, 'Is Ethical Money Financially Smart?', ECGI Finance Working Paper No. 117/2006.

Renneboog, L., J. T. Horst and C. Zhang: 2008a, 'The Price of Ethics and Stakeholder Governance: The Performance of Socially Responsible Mutual Funds', Journal of Corporate Finance 14(3), 302-322.

Renneboog, L., J. T. Horst and C. Zhang: 2008b, 'Socially responsible investments: Institutional aspects, performance, and investor behavior', Journal of Banking and Finance 32(9), 1723 - 1742.

Sirri, E. and P. Tufano: 1998, 'Costly Search and Mutual Fund Flows', The Journal of Finance 53(5), 1589-1622.

Statman, M.: 2000, 'Socially Responsible Mutual Funds', Financial Analysts Journal 56(3), 30-39.

Zhao, Z.: 2004, 'Using Matching to Estimate Treatment Effects: Data Requirements, Matching Metrics, and Monte Carlo Evidence', Review of Economics and Statistics 86(1), 91- 107.

\section{Notes}

${ }^{1}$ Bauer et al. (2005) and Renneboog et al. (2008a) have previously studied the effect of fees on differences in performance between SRI and conventional funds by distinguishing between before-fee and after-fee performance.

${ }^{2}$ See Renneboog et al. (2008b) for a comprehensive survey of the literature on SRI.

${ }^{3}$ We thank Todd Larsen from SIF for providing the reports on which our list of SRI funds is based.

${ }^{4}$ See SIF (2005) for a complete description of their methodology. 
${ }^{5}$ For instance, the mutual fund Lutheran Brotherbood Opportunity Growth Fund was included in SIF reports from 1997 to 2001, but was no longer included in subsequent reports. Similarly, the fund Fidelity Select Environmental was only included in the SIF report of 2005, although it had been operating since 1997. Our inspection of the funds' prospectuses did not reveal any change in the orientation of these funds.

${ }^{6}$ Bauer et al. (2005) and Renneboog et al. (2008a) have recently used this model to evaluate the performance of SRI funds.

${ }^{7}$ Data were downloaded from Kenneth French's website, http://mba.tuck.dartmouth.edu /pages/faculty/ken.french/.

${ }^{8}$ To account for differences in the units used to measure each matching variable and in the dispersion of these variables, the distance metric employed scales the distance according to each of the matching variables by its variance (a procedure also recently employed by Bollen, 2007). More precisely, if the matching variables are size $(s)$, age $(a)$ and size of the management company ( $c$ ), the distance between funds $A$ and $B$ would be:

$d=\sqrt{\frac{\left(s_{A}-s_{B}\right)^{2}}{\sigma_{s}^{2}}+\frac{\left(a_{A}-a_{B}\right)^{2}}{\sigma_{a}^{2}}+\frac{\left(c_{A}-c_{B}\right)^{2}}{\sigma_{c}^{2}}}$

where $\sigma_{k}^{2}$ is the sample variance of variable $k$.

${ }^{9}$ For a more detailed discussion of the matching estimators analysis and a comparison to other methods, see Imbens (2004). For an implementation of the matching estimator used in this paper, see Abadie et al. (2004).

${ }^{10} \mathrm{~A}$ notable exception is the Vice Fund, which focuses on firms in the alcohol, gambling, tobacco, and military sectors.

${ }^{11}$ Results are available from the authors upon request.

${ }^{12}$ These results are available from the authors upon request.

${ }^{13}$ As discussed above, however, the power of the tests is likely to be small due to the small size of the subsample of SRI funds. We note that results are robust to different definitions of intensive screening.

${ }^{14}$ Renneboog et al. (2008a) report that in-house screening is associated with higher risk-adjusted returns for their sample of SRI funds from 23 countries. Renneboog et al. (2008a) also investigate the impact of different types of social screens and of screening intensity and obtain 
mixed results.

${ }^{15}$ We use additional information on the types of screens used by SRI funds (no investment, restricted investment, and positive investment) to perform further robustness tests: We partition the sample of SRI funds according to the number or fraction of positive screens used, and perform cluster analysis to divide the sample into groups with homogeneous screening activity. In our sample, these different methods lead to partitions of the sample and to estimated differences between SRI and conventional funds that are very similar to those obtained when we divide the sample by the number of screens used.

${ }^{16}$ Mutual funds' boards are picked by the management company that runs the fund and many or all funds operated by a management company share the same board.

${ }^{17}$ We note that we obtain the same results (not reported) if we do the matching by fund-year observation rather than by fund. 


\section{Tables}

Table 1: Number and total net assets of SRI and conventional funds

The table shows the number and total net assets (TNA) of SRI and conventional funds in the sample per year. Total net assets are reported in millions of US dollars.

\begin{tabular}{cccccc}
\hline & \multicolumn{2}{c}{ SRI Funds } & & & Conventional Funds \\
\cline { 2 - 3 } \cline { 5 - 6 } & Number of funds & TNA & & Number of funds & TNA \\
\hline 1997 & 31 & 88,774 & & 660 & $1,008,553$ \\
1998 & 41 & 111,272 & & 736 & $1,288,145$ \\
1999 & 42 & 115,505 & & 824 & $1,717,278$ \\
2000 & 47 & 99,517 & & 921 & $1,670,100$ \\
2001 & 56 & 55,113 & & 1,005 & $1,457,958$ \\
2002 & 61 & 36,573 & & 1,102 & $1,138,293$ \\
2003 & 59 & 104,947 & & 1,077 & $1,404,566$ \\
2004 & 60 & 120,962 & & 1,091 & $1,637,126$ \\
2005 & 58 & 141,550 & & 1,060 & $1,749,477$ \\
\hline
\end{tabular}




\section{Table 2: Descriptive statistics}

The table shows descriptive statistics for the SRI and conventional funds in the sample. S.D. denotes standard deviation. Expense ratio and Total loads are reported as percentages. Total loads are the total of all maximum front, deferred, and redemption fees as reported by CRSP. Load funds are defined as funds with a strictly positive value for total loads. Total net assets by fund (TNA, funds) and by management company (TNA, mgmt. co.) are reported in millions of US dollars. Age is reported in years. Turnover stands for the fund's turnover ratio, defined as the minimum of aggregate sales and aggregate purchases of securities, divided by the average 12-month total net assets of the fund. Net returns are the fund's annual returns computed as the sum of monthly returns as reported by CRSP, which are net of expenses. Gross returns are defined as net returns plus the expense ratio. The sample contains 86 SRI funds and 1,761 conventional funds. There are 52 SRI funds and 1,177 conventional funds with a strictly positive total loads for at least one year. The sample period goes from 1997 to 2005 .

\begin{tabular}{lcccccc}
\hline & Mean & S.D. & Median & Mean & S.D. & Median \\
\hline Expense ratio & $1.34 \%$ & $0.47 \%$ & $1.40 \%$ & $1.36 \%$ & $0.47 \%$ & $1.30 \%$ \\
Total loads (all funds) & $1.82 \%$ & $2.29 \%$ & $0.42 \%$ & $2.13 \%$ & $2.25 \%$ & $1.00 \%$ \\
Total loads (load funds) & $3.00 \%$ & $2.25 \%$ & $2.90 \%$ & $3.19 \%$ & $2.05 \%$ & $3.81 \%$ \\
& & & & & & \\
TNA, funds & 1,485 & 6,402 & 196 & 1,034 & 3,610 & 207 \\
TNA, mgmt. co. & 10,747 & 30,315 & 2,364 & 25,867 & 72,808 & 4,699 \\
Age & 11.74 & 12.77 & 7.50 & 11.39 & 11.65 & 7.00 \\
Turnover & 0.709 & 0.601 & 0.588 & 0.982 & 1.100 & 0.740 \\
& & & & & & \\
Net returns & $8.10 \%$ & $8.32 \%$ & $8.61 \%$ & $7.20 \%$ & $9.54 \%$ & $7.90 \%$ \\
& $9.44 \%$ & $8.22 \%$ & $9.82 \%$ & $8.55 \%$ & $9.50 \%$ & $9.18 \%$ \\
\hline
\end{tabular}


Table 3: Differences between SRI and all conventional funds.

The table shows the mean values of several variables of interest for all SRI funds and all conventional funds, as well as differences in means between the two groups. The variables are different measures of before-expense performance (Panel A), after-expense performance (Panel B), and fees (Panel C). A positive sign indicates that the value of the variable is higher for SRI funds. 1- and 4-factor alphas are annual Jensen's and Carhart's alphas, respectively, and are reported as percentages. Fees are in basis points. One, two, and three asterisks denote that the difference is statistically significant at the $10 \%, 5 \%$, and $1 \%$ significance levels, respectively, according to the Welch-Satterthwaite t-test for equality of means of two populations with unequal variances. Standard errors are reported in parentheses. We also report the p-value for the Mann-Whitney (or Wilcoxon) rank sum test.

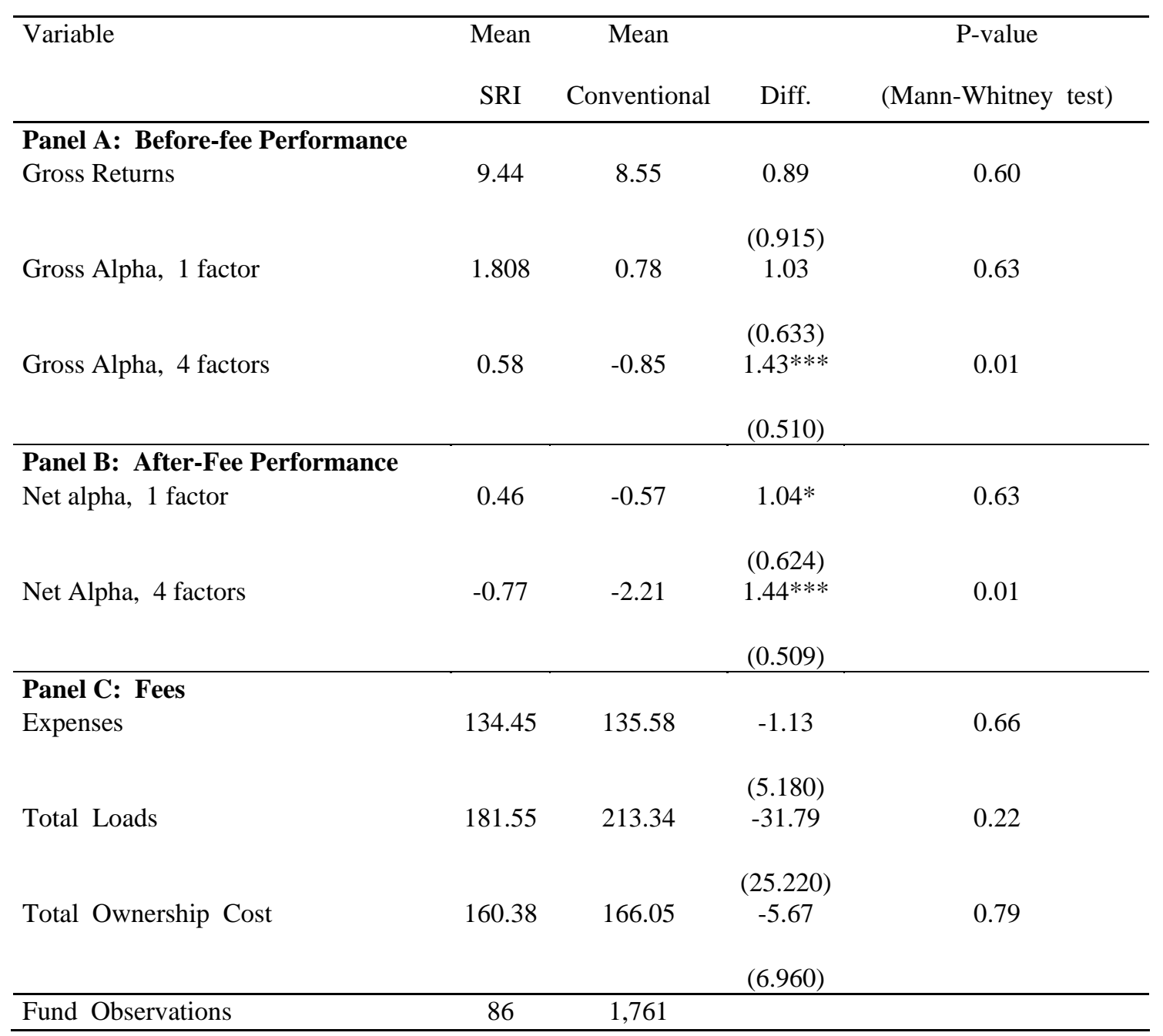


Table 4: Matching estimator analysis for before-expense performance, fund turnover and afterexpense performance.

The table shows the matching estimator results (coefficient, standard error, and mean of the outcome variable for the SRI group) for differences between SRI and matched conventional funds in: before-expense performance (Panel A), fund turnover (Panel B), and after-expense performance (Panel C). A positive sign indicates that the value of the outcome variable is higher for SRI funds. Matching variables include year, investment objective, fund age and total net assets (both in logs), and management company total net assets (in logs). 1- and 4-factor alphas are annual Jensen's and Carhart's alphas, respectively, and are reported as percentages.

\begin{tabular}{|c|c|c|c|c|}
\hline & \multicolumn{2}{|l|}{ Simple } & \multicolumn{2}{|c|}{ Bias Corrected } \\
\hline & 1 match & 4 matches & 1 match & 4 matches \\
\hline \multicolumn{5}{|c|}{ Panel A: Before-fee performance } \\
\hline \multicolumn{5}{|c|}{ Gross Returns } \\
\hline Coeff. & 0.14 & -0.07 & 0.16 & -0.08 \\
\hline S.e. & 1.07 & 0.88 & 1.06 & 0.88 \\
\hline Mean (SRI) & 9.44 & 9.44 & 9.44 & 9.44 \\
\hline \multicolumn{5}{|c|}{ Gross Alpha, 1 factor } \\
\hline Coeff. & $2.04 * *$ & 0.96 & $2.06 * *$ & 0.82 \\
\hline S.e. & 0.91 & 0.72 & 0.91 & 0.72 \\
\hline Mean (SRI) & 1.81 & 1.81 & 1.81 & 1.81 \\
\hline \multicolumn{5}{|c|}{ Gross Alpha, 4 factors } \\
\hline Coeff. & $1.79 * * *$ & $1.03 *$ & $1.83 * * *$ & $0.96 *$ \\
\hline S.e. & 0.67 & 0.57 & 0.67 & 0.57 \\
\hline Mean (SRI) & 0.58 & 0.58 & 0.58 & 0.58 \\
\hline \multicolumn{5}{|c|}{ Gross Alpha, 4 factors (turnover) } \\
\hline Coeff. & $1.49 * *$ & $1.19 * *$ & $1.52 * *$ & $1.20 * *$ \\
\hline S.e. & 0.65 & 0.53 & 0.66 & 0.53 \\
\hline Mean (SRI) & 0.58 & 0.58 & 0.58 & 0.58 \\
\hline \multicolumn{5}{|c|}{ Panel B: Portfolio turnover } \\
\hline Coeff. & -0.15 & $-0.16^{* *}$ & -0.16 & $-0.18^{* *}$ \\
\hline S.e. & 0.10 & 0.08 & 0.10 & 0.08 \\
\hline Mean (SRI) & 0.71 & 0.71 & 0.71 & 0.71 \\
\hline \multicolumn{5}{|c|}{ Panel C: After-fee performance } \\
\hline \multicolumn{5}{|c|}{ Net Alpha, 1 factor } \\
\hline Coeff. & $2.05^{* *}$ & 0.98 & $2.08^{* *}$ & 0.85 \\
\hline S.e. & 0.90 & 0.72 & 0.90 & 0.72 \\
\hline Mean (SRI) & 0.46 & 0.46 & 0.46 & 0.46 \\
\hline \multicolumn{5}{|c|}{ Net Alpha, 4 factors } \\
\hline Coeff. & $1.80 * * *$ & $1.05^{*}$ & $1.85 * * *$ & $0.99 *$ \\
\hline S.e. & 0.67 & 0.58 & 0.67 & 0.57 \\
\hline Mean (SRI) & -0.76 & -0.76 & -0.76 & -0.76 \\
\hline
\end{tabular}


Table 5: Matching estimator analysis for fees.

The table shows the matching estimator results (coefficient, standard error, and mean of the outcome variable for the SRI group) for differences between SRI and matched conventional funds. A positive sign indicates that the value of the outcome variable is higher for SRI funds. Matching variables include year, investment objective, fund age and total net assets (both in logs), and management company total net assets (in logs). Fees are in basis points.

\begin{tabular}{|c|c|c|c|c|}
\hline & \multicolumn{2}{|l|}{ Simple } & \multicolumn{2}{|c|}{ Bias Corrected } \\
\hline & 1 match & 4 matches & 1 match & 4 matches \\
\hline Expenses & -1.31 & -1.98 & -2.09 & -3.57 \\
\hline \multicolumn{5}{|l|}{ Coeff. } \\
\hline S.e. & 6.22 & 4.69 & 6.21 & 4.71 \\
\hline Mean (SRI) & 134.45 & 134.45 & 134.45 & 134.45 \\
\hline Total Loads & 16.96 & -20.03 & 20.68 & -17.87 \\
\hline \multicolumn{5}{|l|}{ Coeff. } \\
\hline S.e. & 33.80 & 25.90 & 33.68 & 25.85 \\
\hline Mean (SRI) & 181.55 & 181.55 & 181.55 & 181.55 \\
\hline \multicolumn{5}{|c|}{ Total Ownership Cost } \\
\hline Coeff. & 1.11 & -4.84 & 0.86 & -6.12 \\
\hline S.e. & 9.86 & 7.25 & 9.85 & 7.26 \\
\hline Mean (SRI) & 160.38 & 160.38 & 160.38 & 160.38 \\
\hline
\end{tabular}


Table 6: Matching estimator analysis by subperiods.

The table shows the matching estimator results (coefficient, standard error, and mean of the outcome variable for the SRI group) for differences between SRI and matched conventional funds in: beforeexpense performance, after-expense performance, and total ownership cost. A positive sign indicates that the value of the outcome variable is higher for SRI funds. Matching variables include year, investment objective, fund age and total net assets (both in logs), and management company total net assets (in logs). 4-factor alphas are annual Carhart's alphas, respectively, and are reported as percentages. Total ownership cost is in basis points.

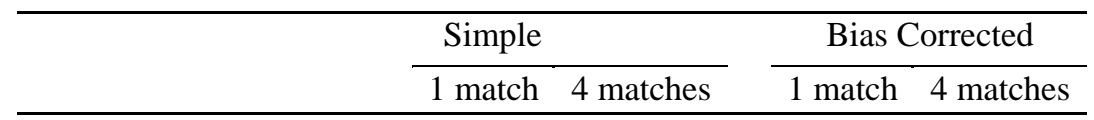

Panel A: 1997-2001

Gross Alpha, 4 factors

Coeff.

S.e.

$\begin{array}{llll}1.45 & 1.13 & 1.49 & 1.08 \\ 1.33 & 1.05 & 1.33 & 1.05 \\ 1.96 & 1.96 & 1.96 & 1.96\end{array}$

Net Alpha, 4 factors

Coeff.

$\begin{array}{llll}1.37 & 1.08 & 1.42 & 1.04 \\ 1.32 & 1.05 & 1.32 & 1.05 \\ 0.59 & 0.59 & 0.59 & 0.59\end{array}$

Mean (SRI)

$\begin{array}{ll}0.59 & 0.59\end{array}$

\section{Total Ownership Cost}

\begin{tabular}{|c|c|c|c|c|}
\hline Coeff. & 8.40 & 4.40 & 8.48 & 3.46 \\
\hline S.e. & 10.57 & 7.95 & 10.59 & 7.95 \\
\hline Mean (SRI) & 161.59 & 161.59 & 161.59 & 161.59 \\
\hline \multicolumn{5}{|c|}{ Panel B: 2002-2005 } \\
\hline \multicolumn{5}{|c|}{ Gross Alpha, 4 factors } \\
\hline Coeff. & 0.81 & 0.26 & 0.78 & 0.24 \\
\hline S.e. & 0.62 & 0.51 & 0.62 & 0.51 \\
\hline Mean (SRI) & -1.00 & -1.00 & -1.00 & -1.00 \\
\hline \multicolumn{5}{|c|}{ Net Alpha, 4 factors } \\
\hline Coeff. & 0.82 & 0.25 & 0.79 & 0.23 \\
\hline S.e. & 0.61 & 0.51 & 0.62 & 0.51 \\
\hline Mean (SRI) & -2.40 & -2.40 & -2.40 & -2.40 \\
\hline \multicolumn{5}{|c|}{ Total Ownership Cost } \\
\hline Coeff. & 4.50 & 1.14 & 4.39 & 1.19 \\
\hline S.e. & 9.80 & 7.50 & 9.80 & 7.54 \\
\hline Mean (SRI) & 169.87 & 169.87 & 169.87 & 169.87 \\
\hline
\end{tabular}


Table 7: Matching Estimator Analysis. Funds with intensive social screening and funds with moderate social screening

The table shows the matching estimator results (coefficient, standard error, and mean of the outcome variable for the SRI group) for differences between SRI and matched conventional funds. In Panel A only SRI funds with 10 or 11 screens are considered. In Panel B only SRI funds with less than 10 screens are considered. There are 15 funds with 10 or 11 screens and 15 funds with less than 10 screens in the sample. A positive sign indicates that the value of the outcome variable is higher for SRI funds. Matching variables include year, investment objective, fund age and total net assets (both in logs), and management company total net assets (in logs). Fees are in basis points.

\begin{tabular}{|c|c|c|c|c|}
\hline & \multicolumn{2}{|l|}{ Simple } & \multicolumn{2}{|c|}{ Bias Corrected } \\
\hline & 1 match & 4 matches & 1 match & 4 matches \\
\hline \multicolumn{5}{|c|}{$\begin{array}{l}\text { Panel A: SRI funds with intensive screening versus matched conventional } \\
\text { funds } \\
\text { Gross Alpha, } 4 \text { factors }\end{array}$} \\
\hline Coefficient & $4.27 * * *$ & 2.01 & $5.00 * * *$ & 1.82 \\
\hline S.e. & 1.48 & 1.91 & 1.73 & 1.94 \\
\hline Mean (SRI) & 1.22 & 1.22 & 1.22 & 1.22 \\
\hline \multicolumn{5}{|c|}{ Net Alpha, 4 factors } \\
\hline Coefficient & $4.09 * * *$ & 1.91 & $4.85^{* * *}$ & 1.74 \\
\hline S.e. & 1.47 & 1.90 & 1.72 & 1.94 \\
\hline Mean (SRI) & -0.22 & -0.22 & -0.22 & -0.22 \\
\hline \multicolumn{5}{|c|}{ Total Ownership Cost } \\
\hline Coefficient & 27.47 & 15.41 & 21.3 & 11.99 \\
\hline S.e. & 20.97 & 15.85 & 20.67 & 15.80 \\
\hline Mean (SRI) & 174.84 & 174.84 & 174.84 & 174.84 \\
\hline
\end{tabular}

Panel B: SRI funds with moderate screening versus matched conventional funds

Gross Alpha, 4 factors

$\begin{array}{lllll}\text { Coefficient } & 1.90 & 1.35 & 1.85 & 1.29 \\ \text { S.e. } & 1.24 & 1.28 & 1.23 & 1.28 \\ \text { Mean (SRI) } & 1.18 & 1.18 & 1.18 & 1.18\end{array}$

Net Alpha, 4 factors

$\begin{array}{lllll}\text { Coefficient } & 1.86 & 1.28 & 1.78 & 1.22 \\ \text { S.e. } & 1.26 & 1.30 & 1.24 & 1.30 \\ \text { Mean (SRI) } & -0.36 & -0.36 & -0.36 & -0.36\end{array}$

Total Ownership Cost

\begin{tabular}{lllll} 
Coefficient & -0.17 & -8.46 & 3.33 & -8.77 \\
S.e. & 23.42 & 18.06 & 23.87 & 18.05 \\
Mean (SRI) & 166.62 & 166.62 & 166.62 & 166.62 \\
\hline *** 1\% sig.; ** 5\% sig.; * 10\% sig. & &
\end{tabular}


Table 8: Matching estimator analysis. Funds with in-house social screening and funds with some external social screening

The table shows the matching estimator results (coefficient, standard error, and mean of the outcome variable for the SRI group) for differences between SRI and matched conventional funds. In Panel A we consider only SRI funds with in-house screening. In Panel B we consider only SRI funds that perform at least part of the social screening outside of the management company that manages the fund's portfolio. There are 17 funds that perform in-house screening only and 11 funds that perform some social screening outside of the fund's management company. A positive sign indicates that the value of the outcome variable is higher for SRI funds. Matching variables include year, investment objective, fund age and total net assets (both in logs), and management company total net assets (in logs). Fees are in basis points.

\begin{tabular}{lccccc}
\hline & \multicolumn{2}{c}{ Simple } & & \multicolumn{2}{c}{ Bias Corrected } \\
\cline { 2 - 2 } \cline { 5 - 6 } & 1 match & 4 matches & & 1 match & 4 matches \\
\hline Panel A: SRI funds with in-house screening versus matched conventional funds \\
Gross Alpha, 4 factors & & & & \\
Coefficient & $4.24^{* * *}$ & 1.98 & & $4.35^{* * *}$ & 2.09 \\
S.e. & 1.59 & 1.91 & & 1.66 & 1.90 \\
Mean (SRI) & 1.41 & 1.42 & & 1.43 & 1.44 \\
& & & & \\
Net Alpha, 4 factors & & & & \\
Coefficient & $4.07^{* * *}$ & 1.86 & & $4.21^{* * *}$ & 2.00 \\
S.e. & 1.58 & 1.90 & & 1.65 & 1.89 \\
Mean (SRI) & -0.12 & -0.13 & & -0.14 & -0.15 \\
& & & & \\
Total Ownership Cost & & & & \\
Coefficient & 13.98 & 8.38 & & 11.94 & 3.65 \\
S.e. & 19.34 & 13.55 & & 19.40 & 13.63 \\
Mean (SRI) & 174.60 & 174.61 & & 174.62 & 174.63 \\
\hline
\end{tabular}

Panel B: SRI funds with some outside screening versus matched conventional funds Gross Alpha, 4 factors

$\begin{array}{lcccc}\text { Coefficient } & 2.24 * * * & 2.23^{* * *} & 2.08^{* * *} & 2.23^{* * *} \\ \text { S.e. } & 0.69 & 0.83 & 0.67 & 0.84 \\ \text { Mean (SRI) } & 1.55 & 1.56 & 1.57 & 1.58\end{array}$

Net Alpha, 4 factors

Coefficient

$\begin{array}{cccc}2.22^{* * *} & 2.17^{* *} & 2.02^{* * *} & 2.18^{* *} \\ 0.80 & 0.91 & 0.78 & 0.92 \\ 0.08 & 0.09 & 0.10 & 0.11\end{array}$

S.e.

$0.08 \quad 0.09$

0.10

0.11

Total Ownership Cost

$\begin{array}{lllll}\text { Coefficient } & 17.48 & 3.73 & 21.47 & 2.68\end{array}$

$\begin{array}{lllll}\text { S.e. } & 31.29 & 24.19 & 30.85 & 24.22\end{array}$

$\begin{array}{lllll}\text { Mean (SRI) } & 172.90 & 172.91 & 172.92 & 172.93\end{array}$

*** 1\% sig.; ** 5\% sig.; * 10\% sig. 
Table 9: Matching estimator analysis for SRI funds managed by the same management company.

The table shows the matching estimator results (coefficient, standard error, and mean of the outcome variable for the SRI group) for differences between SRI funds and matched conventional funds managed by the same management company. A positive sign indicates that the value of the outcome variable is higher for SRI funds. Matching variables include year, fund age and total net assets (both in logs). Fees are in basis points. 4-factor alphas are annual Carhart's alphas reported as percentages.

\begin{tabular}{|c|c|c|c|c|}
\hline & \multicolumn{2}{|l|}{ Simple } & \multicolumn{2}{|c|}{ Bias Corrected } \\
\hline & 1 match & 2 matches & 1 match & 2 matches \\
\hline \multicolumn{5}{|c|}{ Gross Alpha, 4 factors } \\
\hline Coeff. & 0.69 & 0.53 & 1.38 & 0.54 \\
\hline S.e. & 1.23 & 1.15 & 1.21 & 1.09 \\
\hline Mean (SRI) & -0.83 & -0.94 & -0.83 & -0.94 \\
\hline \multicolumn{5}{|c|}{ Net Alpha, 4 factors } \\
\hline Coeff. & 0.90 & 0.69 & 1.68 & 0.73 \\
\hline S.e. & 1.22 & 1.15 & 1.20 & 1.09 \\
\hline Mean (SRI) & -1.94 & -2.02 & -1.94 & -2.02 \\
\hline \multicolumn{5}{|c|}{ Total Ownership Cost } \\
\hline Coeff. & $-25.81 * *$ & $-22.45 * *$ & $-40.28 * * *$ & $-22.66 * *$ \\
\hline S.e. & 10.94 & 11.37 & 12.30 & 11.39 \\
\hline Mean (SRI) & 136.77 & 135.79 & 136.77 & 135.79 \\
\hline
\end{tabular}


Table 10: Matching estimator analysis for SRI funds managed by generalist and specialized management companies.

The table shows the matching estimator results (coefficient, standard error, and mean of the outcome variable for the SRI group) for differences between: SRI funds managed by generalist management companies and matched conventional funds managed by generalist companies (Panel A); SRI funds managed by generalist management companies and matched conventional funds managed by all management companies (Panel B); and SRI funds managed by management companies specialized in SRI and matched conventional funds managed by all management companies (Panel C). Specialized (generalist) management companies offer SRI funds and have more (less) than $50 \%$ of their assets in this type of funds. A positive sign indicates that the value of the outcome variable is higher for SRI funds. Matching variables include year, investment objective, fund age and total net assets (both in logs), and management company total net assets (in logs). Fees are in basis points. 4-factor alphas are annual Carhart's alphas reported as percentages.

\begin{tabular}{lcc}
\hline & 1 match (simple) & 1 match (bias corrected) \\
\hline $\begin{array}{l}\text { Panel A: SRI funds run by generalist management companies versus matched conventional funds run by generalist management } \\
\text { companies }\end{array}$ & & \\
Gross Alpha, 4 factors & -3.09 & $-4.23^{*}$ \\
Coefficient & 2.39 & 2.33 \\
S.e. & -1.2 & -1.2 \\
Mean (SRI) & & \\
Net Alpha, 4 factors & -3.15 & $-4.24^{*}$ \\
Coefficient & 2.41 & 2.35 \\
S.e. & -2.33 & -2.33 \\
Mean (SRI) & & 3.47 \\
Total Ownership Cost & & 18.36 \\
Coefficient & 5.62 & 144.05 \\
S.e. & 18.59 & \\
Mean (SRI) & 144.05 & \\
\hline Panel B: SRI fund run & & \\
\hline
\end{tabular}

Panel B: SRI funds run by generalist management companies versus matched conventional funds run by all management companies

$\begin{array}{lcc}\text { Gross Alpha, } 4 \text { factors } & & \\ \text { Coefficient } & -1.41^{* *} & -1.55^{* *} \\ \text { S.e. } & 0.66 & 0.64 \\ \text { Mean (SRI) } & -1.2 & -1.2 \\ \text { Net Alpha, 4 factors } & & \\ \text { Coefficient } & -1.16^{*} & -1.30^{*} \\ \text { S.e. } & 0.69 & 0.67 \\ \text { Mean (SRI) } & -2.33 & -2.33 \\ \text { Total Ownership Cost } & & \\ \text { Coefficient } & -23.48 & -22.60 \\ \text { S.e. } & 26.64 & 26.44 \\ \text { Mean (SRI) } & 144.05 & 144.05\end{array}$

\begin{tabular}{lcc}
\hline Panel C: SRI funds run by specialized management companies versus matched conventional funds run by all management companies \\
Gross Alpha, 4 factors & $2.76^{* * *}$ & $2.74^{* * *}$ \\
Coefficient & 0.81 & 0.82 \\
S.e. & 1.12 & 1.12 \\
Mean (SRI) & & \\
Net Alpha, 4 factors & $2.70^{* * *}$ & $2.68^{* * *}$ \\
Coefficient & 0.81 & 0.83 \\
S.e. & -0.30 & -0.30 \\
Mean (SRI) & & \\
Total Ownership Cost & 8.56 & 9.08 \\
Coefficient & 9.79 & 9.77 \\
S.e. & 165.33 & 165.33 \\
Mean (SRI) & & \\
\hline *10\% sig $* * *$ 5\% sig $* * * * 1 \%$ sig &
\end{tabular}

* 10\% sig.; ** 5\% sig.; *** $1 \%$ sig. 